\section{THE USE OF CATGUT LIGATURES IN OVARIOTOMY.}

BY SURGEON-MAJOR D. CHAS. DAVIDSON, I.M.S., CIVIL, SURGRON, SATARA, INDIA.

IT has generally been held that catgut ligatures are unsuitable in cases of ovariotomy owing to the danger which may arise from their becoming loosened or absorbed too quickly, but the following case would appear to show that they can be employed with safety. The benefits to be derived from the use of such ligatures in preference to silk, apart from the supposed danger, are sufficiently manifest. The now almost universal procedure of cutting the pedicle short, ligaturing and carefully replacing it in the abdominal cavity, renders the application of the least irritating ligatures compatible with safety desirable, and nothing of this nature that has as yet been introduced into surgical practice has been found to be so little liable to set up inflammation or to so readily undergo absorption as catgut. There is also an advantage in employing it for deep and superficial sutures, especially the former, to the abdominal incision, as it becomes absorbed and there is no occasion to remove the sutures. Indeed the first dressings placed over the wound do not under such circumstances require to be disturbed at all until firm union has taken place, thus saving the patient pain and worry, both liable to set up inflammatory symptoms, and avoiding any danger of interfering with the healing process.

A married Maratha woman, aged about twenty-five, suffering from ovarian tumour, was on June $3 \mathrm{rd}, 1892$, placed on the operating table, and the usual precautions were taken and arrangements made. Surgeon-Major Hill, A.M.S., of the Satara Station Hospital, kindly assisted me. An incision about three inches long was made in the median line midway between the umbilicus and pubes, the deeper layers of fascia and the peritoneum being divided on a director. On passing the hard into the abdomen slight adhesions were found, but not of an extensive nature. The tumour, which was of considerable size and multilocular, was emptied as far as practicable by means of Spencer Wells" "ovariotomy trocar," but part of the contents, being of a semi-solid nature, would not pass through and had to be removed with the tumour. The few adhesions were gently separated and the tumour was turnod out of the abdominal cavity. The pedicle, which was fairly long, was twice transfixed with a needle armed with catgat ligatures which were carefully tied, ligaturing the pedicle in halves. A third ligature of the same material was then thrown round the whole thickness and firmly secured, after which the pedicle was divided and the ligatured portion gently replaced within the abdominal cavity, which was carefully sponged out. The edges of the incision were accurately brought together by means of deep and superficial catgut sutures, and a dressing of iodoform and boracic wool was applied. In the evening, about seven hours after the operation, her condition was as follows : there was no sickness; the temperature was $100.6^{\circ} \mathrm{F}$.; the pulse was 120 , small and soft ; and she was almost free from pain.

June 4th, morning.-Temperature $99^{\circ}$; pulse 102 . She is almost free from pain in the wound, but complains of pain in the head. She passes urine freely, but the bowels have not been opcned. She takes milk well. In the evening the temperature went up to $100 \cdot 8^{\circ}$.

5th. - Temperature in the morning, $99^{\circ} \mathrm{F}$.; in the evening, $101.2^{\circ} \mathrm{F}$ She slept well, but complains of a little pain, chiefly in the right thigh ; the tongue is clean, but the bowels have not, been opened.

6th.- She is going on well. Morning temperature, $99^{\circ}$. evening iemperature, $101.4^{\circ}$.

7th. - She has had no sleep and complains of pain. Temperature $100^{\circ}$.

8th.- 'The bowels have been moved and she slept well. Temperibure $100^{\circ}$. She complains of pain in the wound.

9th.- Temperature normal. She complains of some pain in the right thigh and in the wound. The bowels have been moved.

10th. Temperature normal. She slept well. The bowels have acted.

11th. Temperature normal. She complains of pain and has slight, diarrhoea.

12th. There is severe pain in the wound. She had no sleep till midnight. The bowels acted twice. The temperature is normal. 14th. - Evening tem perature $102 \cdot 1^{\circ}$; pulse 122 . The bowels were moved once. She has nausea and retching.

16th. --Temperature slightly below normal.

17th.- She is free from pain and tenderness. The stools are natural.

From this date she progressed favourably without any bad symptom up to July 2nd, when she was discharged cured, free from any feeling of uneasiness and with the incision firmly united. No sutures were removed from the wound, the catgut having become absorbed, and the dressings were rarely disturbed during the healing process.

\section{ANTISEPTIC MIDWIFERY.}

By CLEMENT GODSON, M.D.ABERD., M.R.C.P.LOND. \&C., CONSUlting PHYSICIAN To The CITY OF LONDON LYING-IN HOSPITAL.

A $T$ the annual meeting of the Governors of the City of London Isying-in Hospital, held in February, it was reported that no death had occurred amongst the women delivered in the hospital during the past year. The last death took place in May, 1891, so that there has been no mortality amongst the mothers for nearly two years; and not only so, but I am able to state, since I am called in consultation to every case of serious illness, that there has not been one arising from septic causes amongst the 907 women delivered during this period. I do not call attention to tbis in a boasting, but in a very thankful spirit, for this hospital has not always been able to report so favourably. In 1870 , when I first became connected with the institution, the mortality during the year was 4 per cent. In the ten years from Jan. 1st, 1873, to Dec. 31st, 1883-the hospital being closed in 1878-the mortality was over 2 per cent. ( 1 in 46$)$. In the four years from January, 1880 , to January, 1884 , it was over 3 per cent. (1 in 32). But during the last six years, that is from January, 1887, to January, 1893 , the death-rate has been 1 in 319 , or 0.31 per cent. This is a remarkable reduction, and naturally one looks for the reason. I have no doubt it results chiefly from the very thorough manner in which the matron sees that the antiseptic management of labour is carried out. Every patient has a vaginal douche of a solution of perchloride of mercury ( 1 in 2000) administered during labour, and another after the delivery of the placenta ; and six more of these douches are given subsequently, generally one night and morning. After this, Condy's fluid or carbolic acid lotions are used. But it is not so much by the use of these douches that immunity from septicæmia is ensured as by the scrupulous attention that is paid to the hands and the finger-nails of all those coming into contact with the patients. It is seen that the nails are kept short, that the nail brush is never neglected, and that after washing the hands in soap and water they are plunged in the sublimate lotion.

In a lecture which I gave in 1887 at the Midwives' Institute on "Antiseptic Midwifery" I spoke of the risk, according to published statements, of mercurial poisoning from the employment of sublimate lotion, and I said that in the fifteen months that it had been universally employed at the City of London Lying-in Hospital not a single instance of it had occurred. I am now able to state that, during six more years of its employment there, no symptom of poisoning by it has been observed, which proves, I think, that all fear of such may be dismissed. Of course it cannot be expected that this absence of mortality amongst the patients can continue for long, for it must be borne in mind that deaths from all causes are included. I, for one, firmly believe in the occurrence of puerperal peritonitis from traumatic causes, injuries during labour, and rupture of a pyosalpinx, for instance; for I have seen such in private practice where the antiseptic management has been most rigidly carried out. But what it is desired to secure, and I believe has been arrived at, is the prevention of puerperal infection being communicated from one patient to another in the lying-in hospitals. Surely this is the time to do honour to Semmelweis, who was the first to point out the causes which gave rise to puerperal fever in lying-in institutions and the means of preventing its occurrence by the use of disinfectants. Dr. Theodore Duka, in a pamphlet published last year, states that in May, 1847, Semmelweis issued orders that, in the clinique under his control in the General Hospital, Vienna, every person, before proceeding to examine any patient, 